\title{
Estimating physiological cost of chemical exposure: integrating energetics and stress to quantify toxic effects in fish ${ }^{1}$
}

\author{
Daniel W. Beyers, James A. Rice, William H. Clements, and \\ Catherine J. Henry
}

\begin{abstract}
We present empirical support for a conceptual framework in which chemical contaminants are considered as sources of physiological stress to fish. Physiological stress was quantified in terms of energy by measuring routine metabolism, food consumption, activity, and growth rates of largemouth bass (Micropterus salmoides) exposed to the organochlorine pesticide dieldrin. Regression analysis was used to estimate models that describe the response of each endpoint as a function of dieldrin concentration and duration of exposure. Metabolic rate, consumption, and growth were influenced by chemical exposure. At short durations of exposure (1-4 days), metabolic rate of exposed fish was depressed compared with controls, but at a longer duration (16 days), metabolic rate increased as a function of concentration. Food consumption and growth rates of fish exposed for 16 days declined as dieldrin concentration increased. The response of each endpoint was consistent with predictions of the general adaptation syndrome. Energetic costs of contaminant-induced changes in metabolism and food consumption can be integrated with a bioenergetics model to demonstrate biological significance of chemical exposure in a natural environment.
\end{abstract}

Résumé : Les auteurs présentent des données empiriques sous-tendant un cadre conceptuel selon lequel les contaminants chimiques constituent une source de stress physiologique pour les poissons. Pour quantifier la valeur énergétique du stress physiologique engendré par ces substances, ils ont mesuré le métabolisme normal, la consommation de nourriture, l'activité et les taux de croissance chez des achigans à grande bouche (Micropterus salmoides) exposés à la dieldrine, un insecticide organochloré. Au moyen d'analyses de régression, ils ont estimé des modèles décrivant les fluctuations de chaque paramètre en fonction de la concentration de dieldrine et de la durée d'exposition. La vitesse de métabolisme, la consommation de nourriture et la croissance variaient en fonction de la durée d'exposition. Le métabolisme des poissons exposés durant de courtes périodes (1-4 jours) était plus lent que celui des poissons témoins. En revanche, en cas d'exposition prolongée (16 jours), le métabolisme s'accélérait en fonction de la concentration de dieldrine, mais la consommation de nourriture et les taux de croissance diminuaient. L'évolution de chaque paramètre était compatible avec les caractéristiques d'un syndrome général d'adaptation. Le coût énergétique des changements intéressant le métabolisme et la consommation de nourriture induits par l'exposition au contaminant peuvent être intégrés dans un modèle bioénergétique pour démontrer le retentissement biologique de l'exposition à un contaminant chimique en milieu naturel.

[Traduit par la Rédaction]

\section{Introduction}

Quantifying the energetic cost of exposure to pollutants has been a recurrent theme in studies of fish living in anthropogenically disturbed environments (Fry 1947; War- ren 1971; Beamish et al. 1975; Rice 1990; Beyers and Sikoski 1994). Much of the appeal of an energetic approach is due to its reliance on first principles of thermodynamics: that matter and energy are conserved. For example, consider a fish with limited resources for meeting the demands of

Received April 6, 1998. Accepted December 9, 1998.

J14543

D.W. Beyers. ${ }^{2}$ Larval Fish Laboratory, Department of Fishery and Wildlife Biology, Colorado State University, Fort Collins, CO 80523, U.S.A.

J.A. Rice. Department of Zoology, North Carolina University, Raleigh, NC 27695-7617, U.S.A.

W.H. Clements. Department of Fishery and Wildlife Biology, Colorado State University, Fort Collins, CO 80523, U.S.A.

C.J. Henry. ${ }^{3}$ U.S. Fish and Wildlife Service, Rocky Mountain Arsenal National Wildlife Refuge, Commerce City, CO 80022, U.S.A.

${ }^{1}$ Contribution 104, Larval Fish Laboratory, Department of Fishery and Wildlife Biology, Colorado State University, Fort Collins, CO 80532, U.S.A.

${ }^{2}$ Author to whom all correspondence should be addressed. e-mail: danb@lamar.colostate.edu

${ }^{3}$ Current address: U.S. Fish and Wildlife Service, Upper Mississippi River National Wildlife and Fish Refuge, McGregor, IA 52157, U.S.A. 
Fig. 1. Conceptual representation of the three stages of the general adaptation syndrome illustrating how energy expenditure for compensating stressor effects changes as a function of time. Modified from Selye (1956).

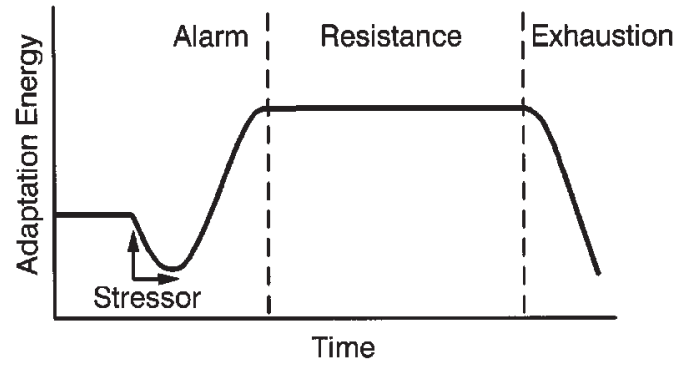

physiological maintenance, growth, and reproduction. If an additional cost like damage from pollutant exposure is imposed upon it, then the fish must reallocate energy expenditures in order to repair the affected system. Reallocation will most likely be reflected by reduced growth or reproduction because energetic expenditures are distributed in a hierarchical fashion and costs of maintenance must be met first (Brett and Groves 1979; Kitchell 1983). Another advantage of an energetic approach is that energy is the common currency of ecology. It provides a means for quantifying the value of available resources as well as associated acquisition costs and can account for physiological effects of suboptimal environmental conditions that may deplete energy reserves. Because of its universal applicability, energy is a useful currency for translating biological effects to higher levels of organization (sensu O'Neill et al. 1986) and is a fundamental component for development of ecological theory about the distribution and abundance of organisms (Hall et al. 1992).

Mechanistic computer models have been developed that summarize the energy budgeting process and growth of fish. An energy budget is a convenient way of illustrating how environmental conditions influence energy expenditures of fish (Warren 1971; Kitchell 1983; Adams and Breck 1990). Basic energy budget equations balance intake from food consumption against the costs of maintenance and growth and have the form

$$
C=R+A+S+F+U+\Delta B
$$

where $C$ is food consumption, $R$ is metabolism, $A$ is activity, $S$ is specific dynamic action (the cost of processing food), $F$ is egestion (feces), $U$ is excretion (urine), and $\Delta B$ is somatic growth and reproductive growth in mature individuals. Growth represents a cumulative, integrated response to the complex of environmental and physiological variables that influence fish (Rice et al. 1983). Because many interacting variables may affect growth (e.g., size, temperature, food availability), it can be difficult to determine which one is primarily responsible for an observed growth pattern. Energetic models can be used to decompose effects of each variable on growth and isolate the contribution from factors of interest. Unfortunately, while study of the energetic cost of pollutant exposure makes sense from an ecological perspective, existing research has not demonstrated how an energetics-based approach can be integrated with traditional theory about contaminant-induced stress in fish.
Selye (1956, 1973) developed a stress concept that describes how external influences affect the physiological condition of organisms. Selye (1973) defined stress as "...the nonspecific response of the body to any demand made upon it..." and he defined the environmental factor that elicits stress as the "stressor". Selye (1956) found that when organisms are exposed to stressors like chemical toxicants, their physiological response follows a pattern that he called the general adaptation syndrome (Fig. 1). It is characterized by three sequential phases. The first phase of the general adaptation syndrome is the stage of physiological alarm. During this stage, the effects of chemical exposure upset homeostasis of the organism. As the organism's physiological systems adjust to compensate for specific effects from the mode of action of the contaminant, a host of nonspecific homeostatic mechanisms are also induced in order to reestablish equilibrium. In fish, this stage may be associated with a loss of appetite, loss of equilibrium, and behavioral changes. The second phase of the general adaptation syndrome is the stage of resistance. This stage occurs when physiological adaptation to the contaminant stressor has been accomplished. During this stage, compensating for the effects of a chemical stressor becomes part of the normal cost of living for an exposed animal. This stage may be associated with increased metabolic rate. Most organisms are not evolutionarily adapted to the energetic costs of compensating for an anthropogenic stressor. Contaminant effects can be compensated for for a while, but if the stressor is of sufficient magnitude and is applied for a sufficient length of time, the third stage of the general adaptation syndrome results: the stage of exhaustion. During this stage, cumulative effects of long-term exposure to a sublethal stressor result in premature death of the individual. In the case of a chemical stressor, mortality occurs because the physiological system responsible for compensating for toxic effects becomes exhausted and stops functioning. Exhaustion occurs because the physiological system has been forced to function at a faster rate than that for which it is evolutionarily adapted.

Selye (1956) measured stress and the progression of the general adaptation syndrome by quantifying physical and biochemical changes in individuals. However, the same ends can be achieved by quantifying the energy expended by an organism to compensate for the effects of chemical exposure. We propose that this be the basis for integration of an ecological energetics-based approach and the Selyean stress paradigm for study of effects of chemical contaminants on fish. By quantifying stress in terms of energy, it should be possible to describe the magnitude of stress (or energetic cost) imposed on fish by chemical exposure. Thus, for this investigation, stress was defined as the change in the energy budget resulting from the combined effects of specific and nonspecific responses to a stressor.

The chemical stressor selected for this investigation was the organochlorine pesticide dieldrin. Dieldrin is presumed to be a general neurotoxin (Joy 1982) that is accumulated in fish from water and food, with bioconcentration from water comprising about $80 \%$ of body burden (Reinhart 1972; D.W. Beyers, unpublished data). Although use of dieldrin in the United States has been banned or voluntarily canceled since 1987, the chemical persists in the sediment and water of several lakes at the Rocky Mountain Arsenal National Wildlife 
Refuge, Commerce City, Colorado (Bergersen 1987). Dieldrin concentrations in the lakes are below the acute criterion (2500 ng. $\left.\mathrm{L}^{-1}\right)$ but may exceed the chronic criterion $\left(1.9 \mathrm{ng} \cdot \mathrm{L}^{-1}\right)$ for protection of freshwater aquatic life (U.S. Environmental Protection Agency 1980; Beyers et al. 1999), and concerns exist about potential sublethal effects on fish from long-term exposure to ambient levels.

The purpose of this investigation was to describe how the energetic budget of fish is affected by dieldrin exposure. This objective was achieved by exposing juvenile largemouth bass (Micropterus salmoides) to dissolved dieldrin concentrations for various lengths of time and then measuring responses that reflect changes in their energetic budget. Measurement endpoints included routine metabolic rate, food consumption, activity, and growth rates. Quantitative relationships describing each response were incorporated into a bioenergetics-based simulation model that is described in a companion paper (Beyers et al. 1999). The bioenergetics model superimposes physiological costs of toxicant compensation and changes in feeding onto the basic energy budget of largemouth bass living in a natural environment. The model can be used to directly compare effects of natural and anthropogenic stressors using energy as a common currency.

\section{Materials and methods}

\section{Experimental animals}

Age-1 largemouth bass were obtained from the Colorado Division of Wildlife, Las Animas State Fish Hatchery (Las Animas, Colorado), and transported to laboratory culture facilities at Colorado State University (Fort Collins, Colorado). Culture facility water temperature was $19^{\circ} \mathrm{C}$. Largemouth bass used in experiments ranged from 30.60 to $103.80 \mathrm{~g}$ with $96 \%$ of the fish ranging from 40.48 to $83.50 \mathrm{~g}$.

\section{Experimental design and exposure system}

Exposure procedures were based on prescribed methods for conducting 32-day early life stage toxicity tests with fishes (American Society for Testing and Materials 1990). Experimental treatments were assigned to replicate aquaria $(n=4)$ using a balanced, factorial, randomized design with five target exposure concentrations $\left(0.00,1000,2000,4000\right.$, and $8000 \mathrm{ng} \cdot \mathrm{L}^{-1}$ dieldrin $)$ and five exposure durations $(1,2,4,8$, and 16 days). One largemouth bass (experimental unit) was randomly assigned to each aquarium. Largemouth bass were transferred from mass cultures to flowthrough exposure aquaria about $24 \mathrm{~h}$ before the toxicant metering system was activated. A continuous-flow diluter was used to generate exposure concentrations. The diluter maintained a 0.5 dilution factor and supplied a volume of $68 \mathrm{~mL} \cdot \mathrm{min}^{-1}$ to glass exposure aquaria. Aquaria were $40 \times 20 \times 25 \mathrm{~cm}$ high, and depth of test solutions was $20 \mathrm{~cm}$. Cool-white fluorescent lamps were the only source of illumination (530 lx), and a $16 \mathrm{~h}$ light : 8 dark photoperiod was maintained.

\section{Physical and chemical conditions}

Dilution water for dieldrin exposures was prepared from tap water (South Adams County Water and Sanitation District, Commerce City, Colorado) treated using two multiple-bed activated carbon systems in series, followed by vigorous aeration for about $8 \mathrm{~h}$ while being heated to a test temperature of $20 \pm 1^{\circ} \mathrm{C}$. The treatment process reduced total residual chlorine concentration to less than the detection limit of $0.02 \mathrm{mg} \cdot \mathrm{L}^{-1}$. Total residual chlorine, alkalinity, hardness, $\mathrm{pH}$, and specific conductance were measured at least twice weekly. Dissolved oxygen was measured daily; water temperature was measured continuously. Dilution water characteristics had the following ranges: dissolved oxygen $6.1-7.3 \mathrm{mg} \cdot \mathrm{L}^{-1}$, alkalinity $44-69 \mathrm{mg} \cdot \mathrm{L}^{-1}$ as $\mathrm{CaCO}_{3}$, hardness $76-107 \mathrm{mg} \cdot \mathrm{L}^{-1}$ as $\mathrm{CaCO}_{3}, \mathrm{pH} 7.5-8.0$, specific conductance $220-310 \mu \mathrm{S} \cdot \mathrm{cm}^{-1}$, and temperature $18-21^{\circ} \mathrm{C}$. Total organic carbon was measured on one occasion at the beginning of the exposure period and was below detection $\left(<1.0 \mathrm{mg} \cdot \mathrm{L}^{-1}\right)$.

\section{Toxicant solutions and analytical procedures}

Purified dieldrin (hexachloro-epoxy-octahydro-endo-exo-dimethanonaphthalene, 98\%) was provided by the Department of Environmental Toxicology, Clemson University (Clemson, South Carolina). Stock solutions were prepared by dissolving dieldrin in pesticide-grade acetone or acetone - dilution water mixtures. The amount of acetone in any exposure concentration never exceeded $0.1 \mathrm{~mL} \cdot \mathrm{L}^{-1}$.

Dieldrin concentrations in aquaria were measured at the beginning, end, and on every third day of the exposure period. On each occasion, three replicate 1 -L samples were collected from each exposure concentration. Replicate samples were obtained from different aquaria. Samples were placed in 1-L amber glass jars with teflon-lined caps and held at $4{ }^{\circ} \mathrm{C}$ until analyzed. A total of four spiked samples were collected on two occasions. All samples were analyzed by the U.S. Army Environmental Hygiene Agency, Organic Environmental Chemistry Division (Aberdeen Proving Ground, Maryland), using a certified method.

\section{Respiration rates}

To estimate the affect of dieldrin exposure on routine metabolism, oxygen consumption of exposed fish was determined using closed static respirometers (Cech 1990). Respirometers were $30 \times$ $15 \times 20 \mathrm{~cm}$ high glass aquaria sealed with glass covers. Oxygen measurements were made using an external water pump that recirculated water from respirometers to an oxygen meter (model 57, Yellow Springs Instrument Company, Yellow Springs, Ohio). Eight respirometers were arranged within a blind so that multiple fish could be processed simultaneously and sampling could be conducted without disturbing the fish. Fish in respirometers were visually isolated from each other. Food was withheld from fish during the 24-h period before respirometry measurements.

At the end of each exposure period, fish and toxicant from each experimental treatment were randomly assigned and transferred to a respirometer. Fish were transferred in dip nets and handling time was less than $15 \mathrm{~s}$. Preliminary studies showed that oxygen consumption rates of fish returned to normal within 15 min of transfer; similar results were reported by Davis and Schreck (1997). Transferred fish were allowed to acclimate for $2 \mathrm{~h}$ under conditions of constant aeration and ambient light (530 lx) and then for $1 \mathrm{~h}$ in complete darkness. Following acclimation, aeration was interrupted and oxygen concentration and temperature of water in the respirometer were measured. Measurements were repeated after about $45 \mathrm{~min}$ had elapsed, and blotted wet mass of each fish was determined to the nearest $0.01 \mathrm{~g}$. Initial dissolved oxygen concentrations typically ranged from 6.9 to $7.2 \mathrm{mg} \cdot \mathrm{L}^{-1}$. Final measurements were made before dissolved oxygen concentrations declined to less than $6.0 \mathrm{mg} \cdot \mathrm{L}^{-1}$. After correcting for biological oxygen demand of respirometers, observed oxygen consumption of each fish was expressed as a mass-specific rate $\left(\mathrm{g} \mathrm{O}_{2} \cdot \mathrm{g} \mathrm{fish}^{-1} \cdot \mathrm{day}^{-1}\right)$.

In order to isolate and quantify the fraction of oxygen consumption attributable to chemical exposure, observed values were compared with expected values calculated for each largemouth bass using an equation given by Hewett and Johnson (1992) for massspecific rate of oxygen consumption:

$$
R=0.00279 \cdot W^{-0.355} \cdot \mathrm{e}^{0.0811 \cdot T}
$$


where $R$ is specific rate of oxygen consumption $\left(\mathrm{g} \mathrm{O}_{2} \cdot \mathrm{g}_{\text {fish }}{ }^{-1}\right.$. day $\left.^{-1}\right), W$ is mass of each largemouth bass $(\mathrm{g})$, and $T$ is temperature of water in the respirometer $\left({ }^{\circ} \mathrm{C}\right)$. The difference $(D)$ between observed and expected rates of oxygen consumption was calculated by subtraction. Values of $D$ were scaled by adding the absolute value of the average difference between observed and expected rates of oxygen consumption for control fish from respective duration of exposure treatments. Thus, scaled $D$ values represented the change in oxygen consumption of largemouth bass due to chemical exposure and will hereafter be referred to as $\Delta$ metabolism. Properties of $\Delta$ metabolism that made it useful in subsequent analyses were that $(i)$ it retained the dimensions and relative scaling of the original data, (ii) values for control fish were distributed around zero, and (iii) fish with higher or lower metabolic rates than expected had positive and negative values, respectively.

\section{Activity}

To measure potential dieldrin-induced changes in activity, movements of largemouth bass were video recorded for the last $45 \mathrm{~min}$ of the ambient-light respirometry-acclimation period. Qualitative observations of fish under low-light conditions (0.05 lx) were also conducted immediately after conclusion of respirometry measurements. These data were evaluated for indications of changes in activity by comparing posture and frequency and rate of movement of unexposed and exposed fish.

\section{Food consumption and growth rates}

Largemouth bass in experimental treatments that had a duration of more than 1 day were fed a weighed ration (blotted wet mass) of live fathead minnows (Pimephales promelas) at a rate of about $2 \%$ of their body mass per day ( $40 \%$ of maximum consumption). Daily food consumption of fathead minnows by largemouth bass was expressed as a specific feeding rate $\left(\mathrm{g}\right.$ prey.g $\operatorname{predator}^{-1}$. day $\left.{ }^{-1}\right)$. Similarly, daily growth of largemouth bass was expressed as a specific rate (g predator.g predator ${ }^{-1} \cdot$ day $^{-1}$ ).

The effect of dieldrin exposure on maximum daily consumption of fathead minnows by largemouth bass ( $\mathrm{g}$ prey.g predator ${ }^{-1} \cdot$ day $^{-1}$ ) was estimated for fish in the 16-day exposure treatment. After conclusion of respirometry measurements, fish in the 16-day treatment were returned to their respective exposure aquaria and were offered a quantified surplus of live fathead minnows. After $24 \mathrm{~h}$, maximum daily consumption was calculated by subtracting the mass of fathead minnows remaining in aquaria from the original quantity. Average mass and total length of fathead minnows were $0.12 \mathrm{~g}$ and $28 \mathrm{~mm}$.

\section{Statistical analysis}

Results of respirometry experiments were analyzed using polynomial regression to estimate the relationship between the dependent variable $\Delta$ metabolism and the explanatory variables measured dieldrin concentration, exposure duration, and their interaction. Data were analyzed with PROC REG (SAS Institute 1990). A general linear model was fit using the method of least squares where the dependent variable was a function of linear, quadratic, cubic, quartic, and the first-order interaction of independent variables. BACKWARD and Akaike's information criterion selection options were used to sequentially eliminate predictors that were unimportant for explaining variation in the dependent variable. Transformations were used if they significantly improved the fit of regression models. Graphical analyses of data and residual plots were conducted to confirm that the final regression model was appropriate and to evaluate compliance with statistical assumptions (Box et al. 1978). The same statistical methodology was applied to analysis of the dependent variables daily food consumption rate, maximum daily food consumption rate, and growth rate as functions of measured dieldrin concentration.

\section{Results}

Toxicant solutions and analytical procedures

Exposure concentrations were adjusted for recovery of dieldrin in spiked samples $(85.0 \%, \mathrm{SE}=6.51)$. Average measured exposure concentrations were 7.16 (control, $\mathrm{SE}=$ 1.29), $963(\mathrm{SE}=31.0), 1840(\mathrm{SE}=140),. 3140(\mathrm{SE}=263)$, and $5790 \mathrm{ng} \cdot \mathrm{L}^{-1}$ dieldrin $(\mathrm{SE}=440$.). The detection limit was $2.86 \mathrm{ng} \cdot \mathrm{L}^{-1}$ dieldrin. Percent recovery of dieldrin decreased as nominal exposure concentrations increased. The most likely explanation for departure from nominal concentrations is that at higher concentrations, dieldrin escaped from aquaria through the process of volatilization (Singmaster 1975). This possibility may also explain why traces of dieldrin were detected in control solutions. The toxicant delivery system was constructed to preclude contamination of control water with dieldrin. The only potential for transfer of dieldrin from exposure to control solutions was through the atmosphere within the chamber surrounding the exposure aquaria.

\section{Respirometry}

Respirometry experiments showed that the response of metabolic rate to dieldrin exposure was complex. Regression analysis of $\Delta$ metabolism as a function of exposure duration and concentration showed that the model that best explained variation in the dependent variable had the form

$$
\begin{aligned}
\Delta \text { metabolism }= & 3.91 \times 10^{-6}-4.19 \times 10^{-7}(\mathrm{DC})+ \\
& 5.41 \times 10^{-11}\left(\mathrm{DC}^{2}\right)+1.76 \times 10^{-8}(\mathrm{DC} \cdot \mathrm{DE})
\end{aligned}
$$

where $\Delta$ metabolism has units $\mathrm{g} \mathrm{O}_{2} \cdot \mathrm{g} \mathrm{fish}^{-1} \cdot \mathrm{day}^{-1}$, DC is dieldrin concentration (ng. $\mathrm{L}^{-1}$ ), and DE is duration of exposure (days). The model accounted for a significant amount of total variation ( $\left.p=0.0003, R^{2}=0.177\right)$ (Table 1$)$. To facilitate model evaluation and use, a three-dimensional graph of $\Delta$ metabolism as a function of exposure concentration and duration was constructed using the regression model (Fig. 2). The model shows that at short durations of exposure, metabolic rate of exposed fish was depressed compared with control fish, but at longer durations of exposure, metabolic rate increased as a function of concentration. These changing relationships are represented in the regression model by the DC.DE interaction term which suggests that the response to dieldrin concentrations was not constant at all exposure durations. The greatest change in metabolic rate occurred at the highest dieldrin concentration and exposure duration. The $\Delta$ metabolism in this treatment was $1.02 \times 10^{-3} \mathrm{~g}$ $\mathrm{O}_{2} \cdot \mathrm{g} \mathrm{fish}^{-1} \cdot$ day $^{-1}$, which was equivalent to a $31 \%$ increase over the average metabolic rate of the 16-day control fish $\left(3.24 \times 10^{-3} \mathrm{~g} \mathrm{O}_{2} \cdot \mathrm{g} \mathrm{fish}^{-1} \cdot \mathrm{day}^{-1}\right)$.

\section{Activity}

Interpretation of activity in ambient-light conditions showed that fish in respirometers tended to rest on the bottom or remain suspended with pelvic fins in contact with the bottom. Occasional exploratory movements were observed but were not more frequent in any experimental treatment. Because dieldrin exposure did not appear to increase activity of largemouth bass under these conditions, no additional interpretation or analyses of movement data were conducted. 
Table 1. Least-squares estimates and significance probabilities for final regression models and their coefficients.

\begin{tabular}{|c|c|c|c|c|}
\hline Response and coefficients & Estimate & SE & $p$ & $R^{2}$ \\
\hline$\Delta$ metabolism & & & 0.0003 & 0.177 \\
\hline Intercept & $3.91 \times 10^{-6}$ & $1.41 \times 10^{-4}$ & 0.9779 & \\
\hline $\mathrm{DC}$ & $-4.19 \times 10^{-7}$ & $1.31 \times 10^{-7}$ & 0.0019 & \\
\hline $\mathrm{DC}^{2}$ & $5.41 \times 10^{-11}$ & $2.08 \times 10^{-11}$ & 0.0106 & \\
\hline $\mathrm{DC} \cdot \mathrm{DE}$ & $1.76 \times 10^{-8}$ & $4.58 \times 10^{-9}$ & 0.0002 & \\
\hline $\log _{10}$ (maximum specific consumption) & & & $<0.0001$ & 0.740 \\
\hline Intercept & -1.27 & $7.31 \times 10^{-2}$ & $<0.0001$ & \\
\hline $\mathrm{DC}^{2}$ & $-1.03 \times 10^{-7}$ & $2.74 \times 10^{-8}$ & 0.0015 & \\
\hline $\mathrm{DC}^{3}$ & $1.36 \times 10^{-11}$ & $4.58 \times 10^{-12}$ & 0.0086 & \\
\hline $\log _{10}$ (specific consumption) & & & $<0.0001$ & 0.599 \\
\hline Intercept & -1.69 & $5.44 \times 10^{-2}$ & $<0.0001$ & \\
\hline $\mathrm{DC}$ & $-1.70 \times 10^{-4}$ & $4.84 \times 10^{-5}$ & 0.0029 & \\
\hline $\mathrm{DC}^{2}$ & $1.81 \times 10^{-8}$ & $7.78 \times 10^{-9}$ & 0.0325 & \\
\hline Specific growth & & & $<0.0001$ & 0.770 \\
\hline Intercept & $3.16 \times 10^{-3}$ & $5.83 \times 10^{-4}$ & $<0.0001$ & \\
\hline $\mathrm{DC}^{2}$ & $-1.36 \times 10^{-9}$ & $2.18 \times 10^{-10}$ & $<0.0001$ & \\
\hline $\mathrm{DC}^{3}$ & $2.04 \times 10^{-13}$ & $3.65 \times 10^{-14}$ & $<0.0001$ & \\
\hline
\end{tabular}

Note: DC, dieldrin concentration $\left(\mathrm{ng} \cdot \mathrm{L}^{-1}\right)$; $\mathrm{DE}$, duration of exposure (days).

Fig. 2. Estimated change in routine metabolic rate for largemouth bass as a function of dissolved dieldrin concentration and duration of exposure. The surface represents the fitted regression. Parameter estimates for the regression model are given in Table 1.

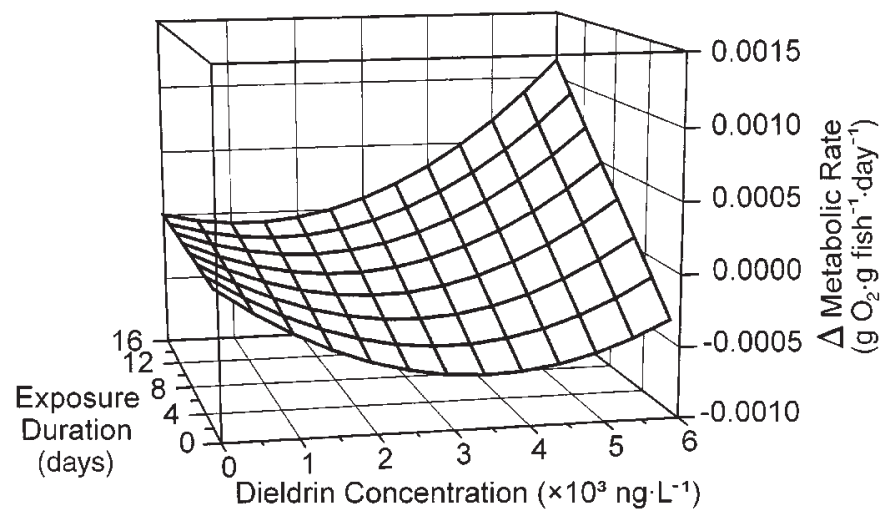

\section{Consumption and growth rates}

Observations of daily feeding by largemouth bass showed that an acclimation period of from 1 to 4 days was required before individual fish in exposure aquaria would readily consume fathead minnows. Because this behavior was demonstrated by largemouth bass in all experimental treatments including the control, it was attributed to adjustment of fish from the mass culture to isolation in small aquaria. Consequently, food consumption and growth estimates for exposure durations of 8 days or less were unreliable or strongly influenced by behavior during the acclimation period. Therefore, only data for fish in the 16-day exposure were used to describe the influence of dieldrin exposure on food consumption and growth.

Maximum specific consumption $\left(\mathrm{g}\right.$ prey $\cdot \mathrm{g}_{\text {predator }}{ }^{-1} \cdot \mathrm{day}^{-1}$ ) of fathead minnows by largemouth bass was reduced by dieldrin exposure (Fig. 3A; Table 1). Regression analysis showed that the model that best explained variation in the dependent variable had the form

$\log _{10}($ maximum specific consumption $)=-1.27-1.03$

$$
\times 10^{-7}\left(\mathrm{DC}^{2}\right)+1.36 \times 10^{-11}\left(\mathrm{DC}^{3}\right) .
$$

The model accounted for a significant amount of total variation $\left(p<0.0001, R^{2}=0.740\right)$. The response of maximum consumption had a sigmoid pattern. At exposure concentrations ranging from 963 to $3140 \mathrm{ng} \cdot \mathrm{L}^{-1}$, maximum consumption rates declined rapidly. At concentrations greater than $3140 \mathrm{ng} \cdot \mathrm{L}^{-1}$, food consumption declined to a minimum value equivalent to about $20 \%$ of the controls. The statistical model suggests that maximum consumption rates declined to a minimum at around $5000 \mathrm{ng} \cdot \mathrm{L}^{-1}$ and then began to increase. This predicted increase is probably an artifact of statistical analysis resulting from a lack of data at concentrations above $5790 \mathrm{ng} \cdot \mathrm{L}^{-1}$. The portion of the relationship influenced by this artifactual effect is illustrated by the broken line in Fig. 3A. Despite this bias at high concentrations, the regression model provides a good description of the response of maximum consumption at concentrations less than $3000 \mathrm{ng} \cdot \mathrm{L}^{-1}$. This includes the concentration range that is relevant to lakes at the Rocky Mountain Arsenal National Wildlife Refuge (<25 ng. $\mathrm{L}^{-1}$, Beyers et al. 1999).

Specific food consumption $\left(\mathrm{g}\right.$ prey $\cdot \mathrm{g}_{\text {predator }}{ }^{-1} \cdot \mathrm{day}^{-1}$ )was also reduced by dieldrin exposure (Fig. 3B; Table 1). All fish were fed at a rate of about $2 \%$ of their body mass per day (40\% of maximum consumption), but only fish in the control treatment ate their entire ration. Regression analysis suggested that the model that best explained variation in the dependent variable had the form

$$
\begin{aligned}
\log _{10}(\text { specific consumption })=-1.69 & -1.70 \times 10^{-4}(\mathrm{DC}) \\
& +1.81 \times 10^{-8}\left(\mathrm{DC}^{2}\right) .
\end{aligned}
$$

The model accounted for a significant amount of total variation $\left(p<0.0001, R^{2}=0.599\right)$. The distribution of the data suggests that, like maximum consumption, the response of 
Fig. 3. Observed (symbols) and predicted (lines) responses of (A) maximum specific consumption, (B) specific consumption, and $(\mathrm{C})$ specific growth of largemouth bass fed fathead minnows after 16 days of exposure to dissolved dieldrin concentrations. The broken lines represent portions of predicted relationships where regression models probably do not accurately describe the response as a function of dieldrin concentration. Parameter estimates for regression models are given in Table 1.
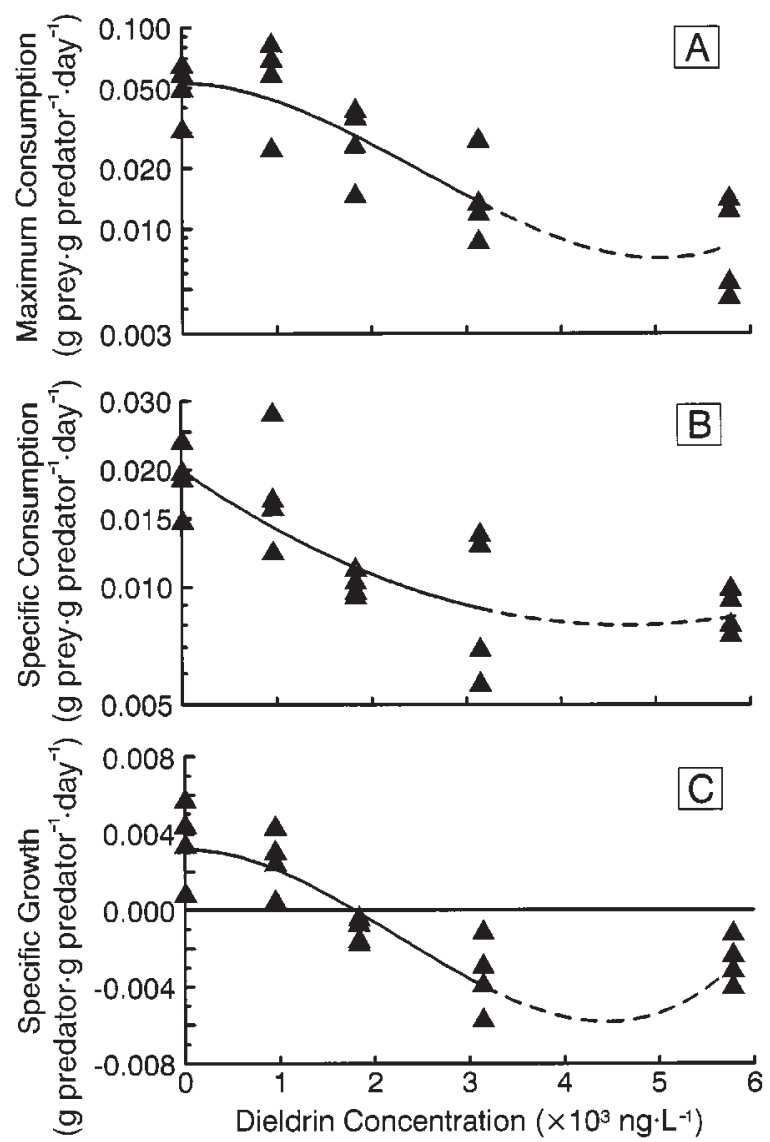

specific consumption had a sigmoid pattern, but the data were inadequate to fit the more complex model. Variability of specific consumption within experimental treatments was more heterogeneous than maximum consumption (Figs. 3A and $3 \mathrm{~B}$ ). In contrast with maximum consumption, specific consumption incorporated responses of largemouth bass during the first few days of chemical exposure when fish were acclimating to the exposure environment as well as the chemical stressor. Thus, individual differences during the acclimation period were reflected in rates of specific consumption, and this variability may have obscured an underlying sigmoid pattern in the response. The lack of data at concentrations above $5790 \mathrm{ng} \cdot \mathrm{L}^{-1}$ influenced the regression analysis for specific consumption in the same way as for maximum consumption (indicated by the broken line in Fig. 3B). However, despite this bias and heterogeneous variance in the data, the model does give an acceptable approximation of the response of food consumption over the concentration range relevant to contaminant levels in the field.

Observed changes in growth of largemouth bass were consistent with the effects on food consumption. There was a significant relationship between specific growth (g predator. g predator ${ }^{-1} \cdot$ day $^{-1}$ ) and dieldrin exposure (Fig. 3C; Table 1). The best regression model had the form

$$
\begin{aligned}
\text { Specific growth }=3.16 \times 10^{-3}-1.36 & \times 10^{-9}\left(\mathrm{DC}^{2}\right) \\
& +2.04 \times 10^{-13}\left(\mathrm{DC}^{3}\right) .
\end{aligned}
$$

The model accounted for a significant amount of total variation $\left(p<0.0001, R^{2}=0.770\right)$. Average growth of largemouth bass in all exposure concentrations was less than the control. Fish in the three highest dieldrin concentrations had negative growth rates as a result of mass loss during the exposure period. Like the previous two models, the regression for growth was influenced by the lack of data at concentrations above $5790 \mathrm{ng} \cdot \mathrm{L}^{-1}$ (indicated by the broken line in Fig. 3C) but provides a good description of the response at environmentally relevant dieldrin concentrations.

\section{Discussion}

\section{Energetic cost of chemical exposure}

We exposed largemouth bass to a gradient of dieldrin concentrations using standard toxicological methods and measured the response to chemical exposure in terms of food consumption, metabolic rate, and growth. Of these three responses, only growth is commonly employed in traditional toxicological studies. However, each of these responses can be translated into energetic equivalents, and they comprise the most important components of a fish bioenergetics model. Bioenergetics models can also simulate effects of fluctuating environmental conditions like water temperature and food abundance. Consequently, a general model can be built that quantifies costs of chemical exposure in fish whose energy budgeting process is simultaneously influenced by environmental fluctuations and changing allometric relationships (Beyers et al. 1999). This generally applicable approach is consistent with the Selyean stress paradigm and the idea that there is no unstressed condition (Selye 1973). Fish constantly expend energy in order to maintain life and offset effects of multiple stressors (Wedemeyer et al. 1984). Daily fluctuations of water temperature, oxygen concentration, and availability of food impose stress on fish that must be compensated for by changes in physiological function and behavior. Numerous processes and changes may occur to achieve compensation, but they all require energy and their importance can be evaluated from an energetic perspective.

\section{Metabolism}

When fish are exposed to chemical stressors, physiological mechanisms are activated in order to maintain homeostasis. If effects of chemical exposure overwhelm homeostatic mechanisms, then damage occurs and repair mechanisms are also activated. Metabolic rate is a good measure of the energy being expended for compensation because it integrates all physiological processes. Our results show that when routine metabolic rate is used as the response variable, the reaction to chemical exposure is complex but is consistent with the general adaptation syndrome. The consistency can be illustrated by isolating (from Fig. 2) the response of $\Delta$ metabolism at one dieldrin concentration (e.g., $5790 \mathrm{ng} \cdot \mathrm{L}^{-1}$ ) as a function of time and comparing it with the response of con- 
Fig. 4. Estimated change in routine metabolic rate for five groups of control fish (open circles) and treated fish (solid circles) exposed to $5790 \mathrm{ng} \cdot \mathrm{L}^{-1}$ dieldrin for $1,2,4,8$, and 16 days. Circles are mean $\pm 1 \mathrm{SE} ; n=4$ except for the second control group where $n=6$. A control group and treatment group were measured on each sampling occasion. The solid horizontal line represents the mean response of control fish. The rising solid line is the fitted regression line for change in metabolic rate as a function of exposure duration for treated fish (this line corresponds to the right edge of the response surface in Fig. 2). Note the similarity to the alarm stage of the general adaptation syndrome (inset).

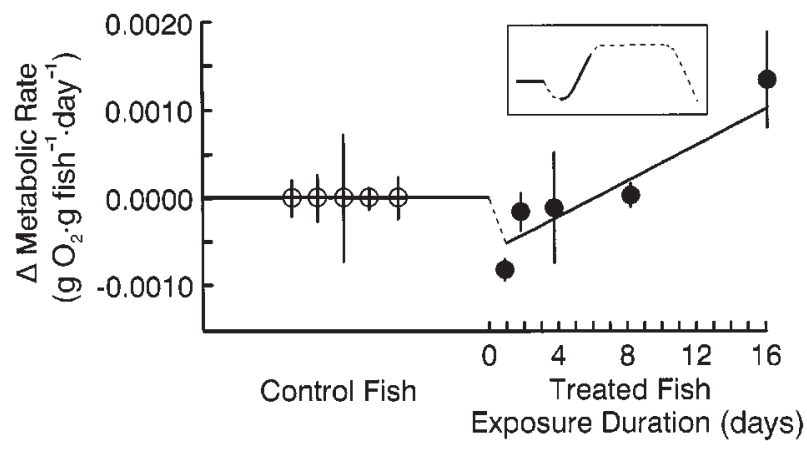

trol fish (Fig. 4). During the first stage of the general adaptation syndrome, the amount of energy for compensating for stressor effects declines and then increases until homeostasis is achieved. Depression of metabolism occurs because the fish is suffering combined effects of a loss of normal ability due to toxic effects and the side effects of the first stage of the general adaptation syndrome (e.g., lethargy and loss of appetite).

Our analysis suggests that after 16 days, largemouth bass were still acclimating to the effects of dieldrin exposure and had not progressed to the second stage of the general adaptation syndrome. Two explanations can be offered for this outcome given that $\Delta$ metabolism cannot increase indefinitely with exposure duration or concentration. First, the duration of exposure may have been too short to allow the general adaptation syndrome to progress to its second stage. This explanation seems plausible for fish in the highest exposure concentrations, but not for largemouth bass in lower concentrations where observed effects of dieldrin exposure were less. A more likely explanation is that the hypothesized progression of the general adaptation syndrome did occur but was not detected by the statistical analysis. The final regression model only explained about $18 \%$ of the total variation in $\Delta$ metabolism. There was a relatively large amount of variation in routine metabolic rate of similar sized individuals that was not accounted for by the statistical analysis. There was also variation associated with measurement of dieldrin concentrations. These sources of variation may have obscured the complex response of the general adaptation syndrome at the four exposure concentrations. Consequently the statistical analysis selected a relatively simple linear relationship for the response of $\Delta$ metabolism as a function of time (Fig. 4). One fish in the highest exposure concentration was nearly overcome by chemical exposure on the last day of the 16-day exposure period and exhibited partial loss of equilibrium and depressed rates of opercular movement. This result suggests that the general adaptation syndrome was progressing and approached the stage of exhaustion for largemouth bass in the highest exposure concentration and duration treatment.

\section{Activity}

Previous studies have demonstrated that exposure to organochlorine chemicals may influence activity of fish (reviewed by Rice (1990) and Heath (1995)). Increased activity or excitability was not observed during this research. However, the increase in metabolic rate of exposed fish at long durations of exposure could have been caused by a slight increase in excitability analogous to a heightened state of alertness. This level of activity would not have been detected by video interpretation and other observations.

\section{Food consumption}

Reduced food consumption frequently accompanies toxicant exposure, especially during the first days of the exposure period (Beyers and Sikoski 1994; Heath 1995). We observed that after 16 days of exposure to dieldrin, maximum and specific consumption of largemouth bass were reduced. The mechanism for suppression of feeding is unknown, but it may be related to physiological effects of the alarm phase of the general adaptation syndrome. Selye (1956, 1973) suggested that loss of appetite is an inherent characteristic of the body's nonspecific response to a stressor. Loss of appetite may be an example of a negative side effect of the stress response. Physiological changes that induce repair mechanisms may reduce ability or desire to process food; consequently, fish demonstrate a loss of appetite (Heath 1995).

\section{Growth}

Largemouth bass were fed a limited ration so that they could not obtain additional energy for compensating for toxic effects by increasing food consumption. Consequently, their growth provided an integrated measure of the stressorinduced changes in food consumption, physiological processes, and activity. Growth rate of largemouth bass declined as a function of increasing dieldrin concentration in a manner similar to food consumption. The sigmoid relationship for growth rate is more complex than typical concentrationresponse models. A basic principle of toxicology is that the magnitude of the response is proportional to the amount of toxicant reaching the site of action; the constant response of growth rate at high concentrations appears to violate this assumption. One explanation is that effects of homeostatic processes that regulate growth and feeding were detected. There might be physiological limitations to the rates that energy reserves can be mobilized to meet combined metabolic costs of maintenance and toxic compensation. Homeostatic mechanisms that govern these processes may prevent negative growth rates from exceeding magnitudes observed in the two highest concentrations. Homeostatic regulation of the motivation to feed is one mechanism that can control growth rate and may be responsible for the observed consumption of prey at high exposure concentrations.

\section{Specific dynamic action, egestion, and excretion}

Specific dynamic action, egestion, and excretion may be influenced by feeding rate, type of food, fish size, and water temperature but are typically considered to be relatively con- 
stant proportions of energy consumed (Elliot 1976; Kitchell 1983). We assumed that these components of the energy budget of largemouth bass were unaffected by exposure conditions. It has been shown that osmoregulation and ion balance are influenced by chemical exposure (Eddy 1981; Wedemeyer et al. 1990), suggesting that excretory processes may also be affected. However, because these processes are governed by homeostatic mechanisms, contaminant-induced changes are probably less important in instances where fish are chronically exposed to low levels of contaminants.

\section{Advantages of integrating energetic and stress concepts}

Investigations of contaminant-induced stress in fish often emphasize detection of departures from biochemical and physiological norms. The Selyean concept of stress and the idea that living organisms are constantly compensating for effects of environmental stressors suggest that normal physiological conditions change over time and are dependent on individual and environmental characteristics (Wedemeyer et al. 1984; Heath 1995). Consequently, establishing what is "normal" may not be as useful as estimating the relative change in a physiological response due to chemical exposure. For example, our experiments revealed the relative change in food consumption, metabolism, activity, and growth attributable to chemical exposure. Establishing whether fish in the control treatment were normal was of little interest compared with quantifying the changes in exposed largemouth bass relative to control fish.

The magnitude of stress that can be tolerated by an organism is not dependent on whether the source of the stressor is natural or anthropogenic; rather, it is a function of how well the animal is equipped to compensate for the effects of exposure. Compensatory ability of an organism in a given environment is dependent on its evolutionary history and the reserve energy that can be allocated to offset effects of a new stressor. Cumulative effects of multiple stressors can deplete an organism's reserves, thereby reducing its ability to cope. Conversely, organisms in relatively benign environments with abundant food may have large energetic reserves that can be mobilized to maintain homeostasis. The environmental background that an organism lives in plays an important role in its ability to compensate for effects of contaminant exposure.

Traditional toxicological methods do not quantitatively account for cumulative effects of contaminant exposure and environmental conditions. We propose that quantifying the cost of contaminant-induced physiological stress in terms of energy provides a basis for integrating the effects of natural and anthropogenic stressors. By mechanistically linking laboratory-derived concentration-response relationships with a bioenergetics model, the physiological costs of chemical exposure can be superimposed onto the basic energy budget of a fish living in a naturally fluctuating environment (Beyers et al. 1999). The integrated model can be used to demonstrate the biological significance of contaminant exposure by quantifying the relative change in energy budgets of exposed and unexposed fish.

\section{Acknowledgments}

We are grateful to Jennifer Kleffner, Ryan Poole, and
Mark Pearson for their diligent assistance during construction and experimental phases of this research. Stephen Smith, Pat Gustafson, and Terry Brown contributed to the success of experimental studies conducted at the CERCLA Waste Water Treatment Plant, Rocky Mountain Arsenal National Wildlife Refuge. We also thank Kevin R. Bestgen for clarifying aspects of the statistical analysis. We are also grateful to John Roff, Alan Heath, and three anonymous reviewers for comments that improved the manuscript. This investigation was funded by the Department of the Interior, U.S. Fish and Wildlife Service, contract No. 14-16-0009-1552.

\section{References}

Adams, S.M., and Breck, J.E. 1990. Bioenergetics. In Methods for fish biology. Edited by C.B. Schreck and P.B. Moyle. American Fisheries Society, Bethesda, Md. pp. 389-415.

American Society for Testing and Materials. 1990. Standard guide for conducting early life-stage toxicity tests with fishes. E124188. In Annual book of ASTM standards. Vol. 11.04. American Society for Testing and Materials, Philadelphia, Pa. pp. $827-$ 852.

Beamish, F.W.H., Niimi, A.J., and Lett, P.F.K.P. 1975. Bioenergetics of teleost fishes: environmental influences. In Comparative physiology: functional aspects of structural materials. Edited by L. Bolis, S.H.P. Maddrell, and K. Schmidt-Nielsen. American Elsevier Publishing Company, New York. pp. 187209.

Bergersen, E.P. 1987. Aldrin, dieldrin, and mercury profiles in recent lake sediments at the Rocky Mountain Arsenal, Colorado. Arch. Environ. Contam. Toxicol. 16: 61-67.

Beyers, D.W., and Sikoski, P.J. 1994. Acetylcholinesterase inhibition in federally endangered Colorado squawfish exposed to carbaryl and malathion. Environ. Toxicol. Chem. 13: 935-939.

Beyers, D.W., Rice, J.A., and Clements, W.H. 1999. Evaluating biological significance of chemical exposure to fish using a bioenergetics-based stressor-response model. Can. J. Fish. Aquat. Sci. 56. This issue.

Box, G.E.P., Hunter, W.G., and Hunter, J.S. 1978. Statistics for experimenters. John Wiley \& Sons, New York.

Brett, J.R., and Groves T.D.D. 1979. Physiological energetics. In Fish physiology. Vol. 8. Edited by W.S. Hoar, D.J. Randall, and J.R. Brett. Academic Press, New York. pp. 279-352.

Cech, J.J. 1990. Respirometry. In Methods for fish biology. Edited by C.B. Schreck and P.B. Moyle. American Fisheries Society, Bethesda, Md. pp. 335-362.

Davis, L.E., and Schreck, C.B. 1997. The energetic response to handling stress in juvenile coho salmon. Trans. Am. Fish. Soc. 126: $248-258$.

Eddy, F.B. 1981. Effects of stress on osmotic and ionic regulation in fish. In Stress and fish. Edited by A.D. Pickering. Academic Press, New York. pp. 77-102.

Elliot, J.M. 1976. The energetics of feeding, metabolism and growth of brown trout (Salmo trutta L.) in relation to body weight, water temperature and ration size. J. Anim. Ecol. 45: 923-948.

Fry, F.E.J. 1947. Effects of the environment on animal activity. Univ. Toronto Stud. Biol. Ser. No. 55.

Hall, C.A.S., Stanford, J.A., and Hauer, F.R. 1992. The distribution and abundance of organisms as a consequence of energy balances along multiple environmental gradients. Oikos, 65: $377-$ 390.

Heath, A.G. 1995. Water pollution and fish physiology. 2nd ed. Lewis Publishers, New York. 
Hewett, S.W., and Johnson, B.L. 1992. Fish bioenergetics model 2. Tech. Rep. Univ. Wis. Sea Grant Inst. No. WIS-SG-92-250.

Joy, R.M. 1982. Mode of action of lindane, dieldrin, and related insecticides in the central nervous system. Neurobehav. Toxicol. Teratol. 4: 813-823.

Kitchell, J.F. 1983. Energetics. In Fish biomechanics. Edited by P.W. Webb and D. Weihs. Praeger, New York. pp. 312-338.

O'Neill, R.V., DeAngelis, D.L., Waide, J.B., and Allen, T.F.H. 1986. A hierarchical concept of ecosystems. Princeton University Press, Princeton, N.J.

Reinhart, R.E. 1972. Accumulation of dieldrin in algae, Daphnia magna, and the guppy. J. Fish. Res. Board Can. 29: 1413-1418.

Rice, J.A. 1990. Bioenergetics modeling approaches to evaluation of stress in fishes. Am. Fish. Soc. Symp. 8: 80-92.

Rice, J.A., Breck, J.E., Bartell, S.M., and Kitchell, J.F. 1983. Evaluating the constraints of temperature, activity and consumption on growth of largemouth bass. Environ. Biol. Fishes, 9: 263275.

SAS Institute. 1990. SAS/STAT users guide, version 6, edition 4. Vol. 2. SAS Institute Inc., Cary, N.C.

Selye, H. 1956. The stress of life. McGraw-Hill Book Company, New York.
Selye, H. 1973. The evolution of the stress concept. Am. Sci. 61: 692-699.

Singmaster, J.A. 1975. Environmental behavior of hydrophobic pollutants in aqueous solutions. Ph.D. thesis, University of California, Davis, Calif.

U.S. Environmental Protection Agency. 1980. Ambient water quality criteria for aldrin/dieldrin. EPA 440/5-80-019. U.S. Environmental Protection Agency, Washington, D.C.

Warren, C.E. 1971. Biology and water pollution control. W.B. Saunders Company, Philadelphia, Pa.

Wedemeyer, G.A., McLeay, D.J., and Goodyear, C.P. 1984. Assessing the tolerance of fish and fish populations to environmental stress: the problems and methods of monitoring. In Contaminant effects on fisheries. Edited by V.W. Cairns, P.V. Hodson, and J.O. Nriagu. John Wiley \& Sons, New York. pp. 163-278.

Wedemeyer, G.A., Barton, B.A., and McLeay, D.J. 1990. Stress and acclimation. In Methods for fish biology. Edited by C.B. Schreck and P.B. Moyle. American Fisheries Society, Bethesda, Md. pp. 451-489. 